\title{
Prácticas
}

\section{en tiempos de covid}

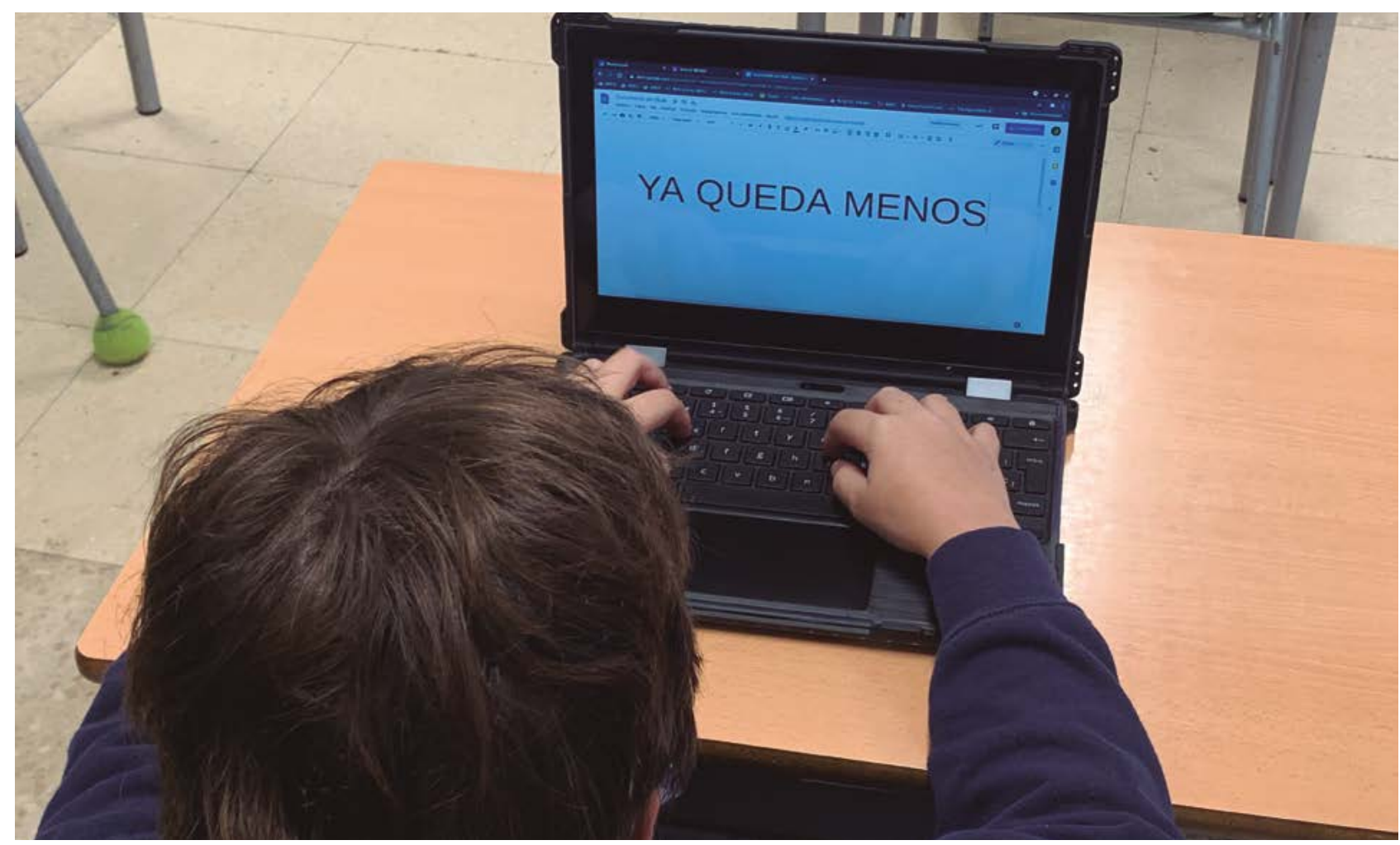

La COVID-19 ha cambiado en menos

de un año la práctica educativa a la que

estábamos acostumbrados. En este artículo pretendemos dar nuestra visión de la

perspectiva como alumnas en prácticas en

los colegios. Pretendemos reflejar todos los

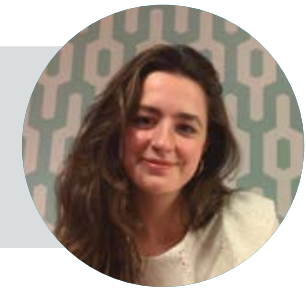

\section{nueva realidad educativa desde nuestra}

cambios que la pandemia ha ocasionado y

cómo los colegios han sabido afrontarlos. 


\section{Agradecimientos}

Cuando la tempestad parece haber acabado con todo, siempre hay alguien que lanza su red para permitir que otros pasen y sigan caminando. Qué mejor manera de comenzar este artículo que mostrando nuestro agradecimiento a todos aquellos que nos están permitiendo continuar caminando, a todos los colegios y maestros que están haciendo posible que nuestra formación siga su curso, que nuestro aprendizaje no decaiga; más bien, al contrario, están consiguiendo que se vuelva un reto en estos tiempos que vivimos. Circunstancias difíciles, donde la docencia y el día a día en el aula se están convirtiendo en una novedad que presenta retos inimaginables para todos. A pesar de ello, son muchos los que un año más han decidido recibir a alumnos de prácticas, a pesar de todas las dificultades que esta coyuntura está presentando parece no impedirles lanzarse a acoger a estudiantes de distintos cursos. Alumnos que con incertidumbre afrontábamos los primeros meses, sin saber qué ocurriría con nuestras tan deseadas prácticas. Poco a poco parecía que esa intranquilidad se calmaba y que, por fin, llegaría el día de volver a un colegio. No podemos estar más agradecidas por ello, por permitirnos comenzar con ilusión estas prácticas que parecían lejanas pero que por fin llegaron. Nuestro más sincero agradecimiento a todos estos maestros y centros educativos que nos están ayudando a crecer personal y profesionalmente incluso en situaciones adversas.

\section{Protocolos}

Situaciones excepcionales requieren medidas excepcionales.

Cuando a finales de verano se planteó la vuelta a las aulas, pocos ocultaban el temor al repunte de casos por la vuelta a los colegios: las imágenes a las que estábamos acostumbrados de niños jugando en los patios, comiendo en comedores... hacían difícil pensar en una vuelta del todo segura a las aulas.

Sin embargo, gracias a los protocolos que todos los colegios han seguido riguro-

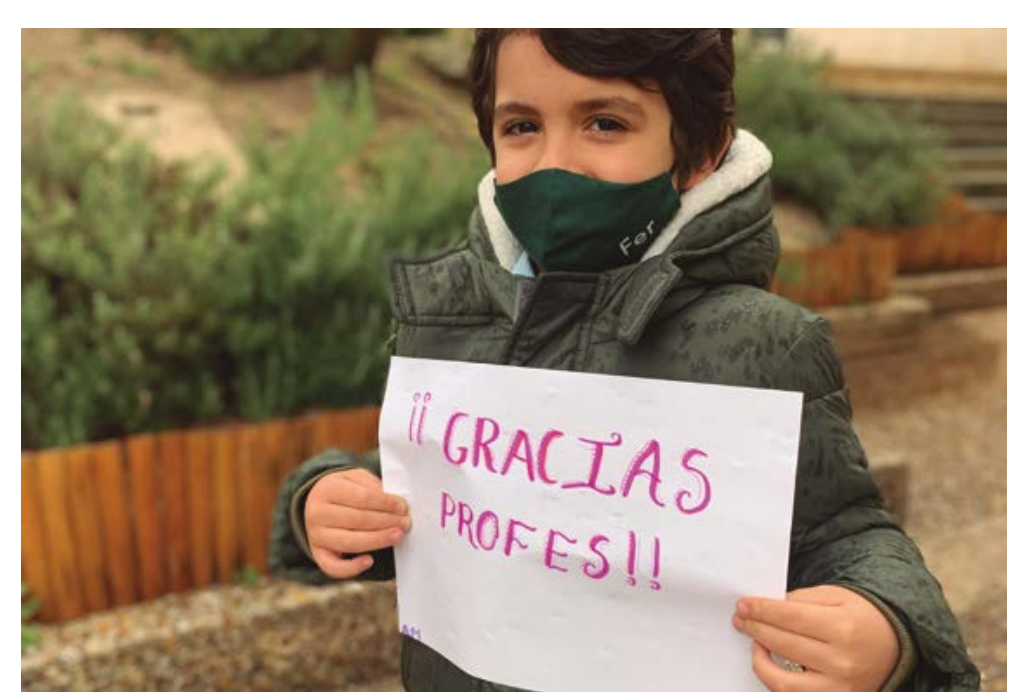

samente se ha logrado de manera eficaz frenar los contagios en el ámbito escolar. Todos los espacios de los centros educativos han sufrido cambios para adaptarse a los diferentes protocolos.

Empezando por las aulas: cualquiera que entre a una de ellas observará la fila de alumnos que buscan lavarse las manos con gel hidroalcohólico para después ocupar sus asientos separados de los demás por la distancia de seguridad. La palabra individual está más presente en su día a día que nunca: puestos individuales, material individual que no podrán compartir, a menos que sea previamente desinfectado...

Los patios que observamos en nuestras prácticas también son distintos a los que recordamos de nuestra etapa escolar al aplicarse el protocolo necesario: cada grupo burbuja ocupa una parcela del patio separada de los demás. A la hora de comer los niños también se separan ya que ello implica bajarse la mascarilla.

En los comedores se aplica un procedimiento parecido: Ios alumnos de un grupo burbuja comerán juntos y la mascarilla deberá colocarse en cuanto terminen. En algunos centros incluso se han instalado mamparas para que cada alumno cuente con su propio espacio.

Las entradas y salidas también han sido modificadas: se han olvidado ya las aglomeraciones de niños al salir del colegio, ahora cada clase sale por separado, dejando tiempo y distancia respecto al resto. Los horarios de los diferentes cursos se han modificado para evitar coincidencias y aglomeraciones tanto a las entradas como a las salidas. 


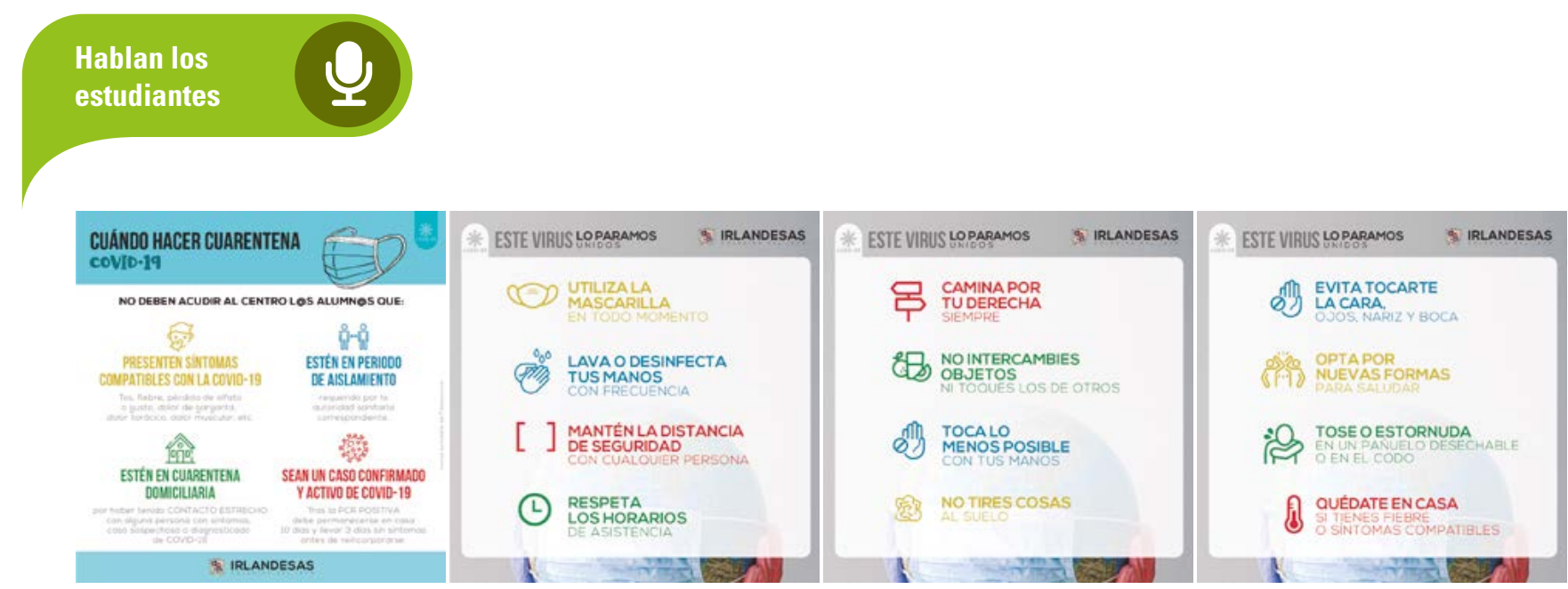

Protocolo anti-COVID-19 Colegio B. V. María Irlandesas - El Soto
En todos estos espacios están presentes dos medidas clave para frenar la expansión del virus: uso obligatorio de mascarilla y ventilación constante de aulas, comedores, despachos, salas de reuniones...

\section{Actitud de los alumnos}

Todas las medidas que venimos comentando se han confeccionado para garantizar la seguridad en las aulas tanto para los alumnos como para los profesores. Si bien normalmente son los primeros los que aprenden de los docentes, esta situación pandémica ha provocado una vuelta de tornas.

Cuando comenzamos nuestras prácticas lo que más nos sorprendió no fue una práctica docente o una metodología innovadora. Lo que sin duda más Ilamó nuestra atención fue la actitud de los alumnos frente a las nuevas situaciones y protocolos. Si por un momento imaginamos volver a nuestra infancia para vivir esta pandemia, nos vienen a la mente multitud de críticas y disgustos por no poder jugar con los amigos de otras clases, por la molestia de las mascarillas, por no poder hacer trabajo colaborativo... Sin embargo, la actitud de los niños es, sin duda, ejemplar: no hay quejas, cumplen las medidas rigurosamente, incluso en ocasiones, nos recuerdan a los maestros que no nos despistemos y cumplamos todas las medidas necesarias. Esta situación nos recuerda cada día que no solo los adultos son capaces de enseñar y ser ejemplo.

\section{Las aulas}

Ante las circunstancias que estamos atravesando, son muchos los cambios que se han tenido que afrontar. Uno de los más significativos reside en las aulas. Son innumerables las múltiples transformaciones que los colegios han tenido que ir haciendo en estos tiempos, para poder cumplir y garantizar las medidas de seguridad oportunas. Por ello, muchos se han tenido que reinventar, transformando lugares como laboratorios, gimnasios o salones de actos en nuevas clases, convirtiendo bibliotecas en "salas covid" donde los alumnos puedan quedarse en el caso de presentar síntomas; o incluso, pasillos que han tomado la forma de pequeñas aulas. Nada parece haber sido un impedimento para comenzar de nuevo la vida escolar. El objetivo era aunar ideas y conocimientos para poder encontrar un lugar apto para los alumnos, donde un año más, pudiesen volver a sus colegios, listos para aprender en tiempos de pandemia.

En muchas ocasiones las aulas parecen haber adquirido un matiz distinto. Donde antes las mesas se colocaban en grupos, para que los alumnos pudiesen estar todos juntos trabajando de manera cooperativa, ahora la distancia marca la relevancia. Esta ha pasado a ser un factor indispensable a tener en cuenta en el día a día en las clases. A pesar de todas estas medidas, nuevas normas y maneras de trabajar, tanto colegios como alumnos y maestros han sido capaces de adaptarse, poniendo en valor y primando, por encima de todo, la educación, la formación y el desarrollo, tanto a nivel individual como de grupo. Se demuestra una vez más, la capacidad de adaptación del ser humano para afrontar retos y dificultades.

\section{Las prácticas y nuestra formación}

Cuando la realidad se impone a lo estudiado en la universidad descubrimos la importancia de las prácticas. Son muchos los contenidos que estudiamos cada día en las aulas, conceptos necesarios e imprescindibles para nuestra formación, pero que solo adquieren sentido cuando estamos delante de un grupo de alumnos, que nos exigen poner a prueba todo lo que estamos apren- 
diendo. Qué mejor manera de descubrir algo que siendo partícipe de ello. Las prácticas son sin duda un pilar fundamental en nuestra formación, son el lugar donde todo comienza a cobrar sentido, donde las dificultades inimaginables se revelan con ímpetu ante nosotras. Solo en ellas, hemos sido capaces de afrontar situaciones impensables, pero también de no dejar de aprender. La teoría sin la práctica es inconcebible y menos en una profesión como la nuestra, donde vives rodeado de pequeñas personas únicas y completamente diferentes. Cada día descubres un nuevo reto, te llevas contigo un aprendizaje distinto y todo gracias a unas prácticas que nos están permitiendo crecer, no solo a nivel profesional o académico, sino personal. Son un tiempo de continuo aprendizaje y cambio, donde gracias a esta experiencia estamos descubriendo distintas metodologías, estilos de enseñanza, profesores y maneras de estar ante tus compañeros y alumnos. Poco a poco vamos definiendo nuestro papel como maestras, descubriendo qué nos gusta más y menos o detectando aspectos que a nuestro juicio haríamos de otra manera. Día a día vamos definiendo nuestro ser como futuras maestras.

\section{Final: vuelta a la normalidad}

A lo largo de todo el artículo hemos querido destacar la capacidad de adaptación del ser humano ante las circunstancias que le sobrevengan. En este caso, en particular, quizá es algo más fácil adaptarnos a esta situación ya que sabemos que algún día, esperamos que más pronto que tarde, esta acabará y volveremos paulatinamente a la normalidad.

\section{HEMOS HABLADO DE}

\section{COVID-19; pandemia; prácticas; colegios; adaptación.}

Este artículo fue solicitado por PADRES Y MAESTROS en septiembre de 2020, revisado y aceptado en febrero de 2021.
Todos, tanto a nivel laboral como personal, hemos hecho esfuerzos para adaptarnos y hacer de esta situación la mejor posible, sin embargo, todos deseamos indudablemente volver a nuestra vida de antes. Por supuesto, los maestros (y alumnos en prácticas como nosotras) desean conocer las caras de los niños a los que educan, poder abrazarlos cuando estos consiguen logros, por pequeños que sean, volver a ver sus alegres sonrisas y joviales rostros. Los niños no ven el momento de volver a jugar a la pelota en los patios con amigos de otras clases. Nosotras, como alumnas de Educación, deseamos con esperanza que nuestras prácticas del próximo año dejen de ser prácticas en tiempos de covid para ser, simplemente, prácticas •

\section{Da) DRRA SABER MÂS}

Comunidad de MAdrid (2 de octubre 2020). Protocolo de actuación ante la aparición de casos COVID-19 en centros educativos de la Comunidad de Madrid. Recuperado de https://www.comunidad. madrid/sites/default/files/doc/sanidad/epid/protocolo_actuacion_casos_covid-19_en_centros_educativos_cm.pdf

Organización Mundial de La Salud (18 de septiembre 2020). Preguntas y respuestas sobre las escuelas y la COVID-19. Recuperado de https:// www.who.int/es/emergencies/diseases/novel-coronavirus-2019/ question-and-answers-hub/q-a-detail/q-a-schools-and-covid-19

Rodriguez, E. (19 de noviembre de 2020). Coronavirus en Asturias. Los universitarios que hagan prácticas en colegios deberán limitar su vida social. Recuperado de https://www.elcomercio.es/asturias/universitarios-hagan-practicas-colegios-limitar-vida-social20201119000357-ntvo.html 